\title{
The Relationship Between Organizational Value Sharing and Influence Over Strategic Decisions
}

\author{
Cathy A. Enz \\ Indiana University
}

\begin{abstract}
This study examines the relationship between influence in the strategic decisionmaking process and the sharing of organizational values. Findings from a quick service restaurant chain indicate that perceptions of value sharing are associated with the ability to influence critical strategic issues. The assessed ability of various corporate departments to influence specific strategic decisions differs according to the type of value shared and the degree of value sharing. Few differences in results exist as a function of value sharing with the top management team (vice presidents) versus value sharing with the founder/CEO. Implications of the results and the need to continue empirical exploration of value-based explanations for strategic decision making are discussed.
\end{abstract}

It is commonly accepted that values influence strategic decisions (Andrews 1980; Barnard 1938; Barney 1986; Child 1972; Lorange 1980; March and Simon 1958; Selznick 1957).Although it is acknowledged that values have an influence on strategic decisions, there has been little empirical exploration of this relationship. In addition, much of the literature in strategy stresses an economic approach in which strategic decisions are based on organizational capabilities, environmental constraints and the allocation of resources. These approaches to strategy formulation have relied heavily on the microeconomic assumption that a unitary set of organizational values guide the firm (Murray 1978; Narayanan and Fahey 1982). This assumption has allowed much of the work on strategic decision making to neglect the possibility that value differences exist and influence the process of strategy making. Strategic decision making is thought to be a rational process in which top managers examine the organization's external environment and internal capabilities and then select the optimal strategy.

Recently, researchers have begun to criticize the economic approaches to strategic decision making as inaccurately representing the process. Murray (1978) suggests that strategic decisions are fragmented and disjointed, and the process resembles negotiation among parties rather than a rational step-by-step process. Simon (1957) has claimed that a rational search and decision-making process, while desirable, is not what takes place in reality. A political orientation to strategic decision making is presented as an alternative to the rational-economic 
model and suggests that various subunits or coalitions endeavor to influence strategic decisions (Mintzberg, Raisinghani, and Theoret 1976; Narayanan and Fahey 1982). Their influence attempts emerge from a foundation of varied beliefs, perceptions, and value orientations. These subunits operate with different frames of reference, oftentimes represented in their professional attachments (e.g., accounting versus marketing), while spawning differing conceptions of what the organization should value. Departments are the focus of the present study because they are the fundamental organizational units that carry out strategic plans and are also the influences of strategic decisions.

According to Andrews (1980), there is no way to divorce strategy from the values of organizational participants. Executives work cooperatively to formulate and implement strategy requiring the exchanging and sharing of values. Blau (1967) notes that value sharing makes social exchange possible and hence becomes a critical component of any attempt to manage strategically. Hambrick and Mason (1984) recently argued that the values of top management filter their perceptions of the organization and the environment. Earlier, March and Simon (1958) and Child (1972) suggested that top managers bring their values to bear on the decisionmaking process. More recently, Enz (1986) has shown that employees in different subunits are guided by their shared values and that these values vary from one functional unit to another. Clearly the importance of values does not stop with the executives. Departments in the position of implementing strategic choices must also have employees who share organizational values if conflict is to be avoided and if the department is to influence the decision-making process.

In the present study it is argued that the perceived ability of a department to influence strategic issues is related to the value sharing between members of the department and top management. Members of different functional units may not share the same organizational values, and the possibility of conflicting and contradictory values may significantly influence the involvement or impact of various departments on strategic decision making. Those departments thought to be most value congruent with top management would appear to be more likely to influence strategic decisions. This influence may be unwarranted, given environmental factors, or detrimental to the overall functioning of the firm but may exist nonetheless.

For the purpose of clarity, the values of interest in this study are defined as those pertaining to the organization. Organizational values are the beliefs held by a group or individual that speak to the actions or goals (ends) organizations "ought to" or "should" identify in the running of the firm (Enz 1986). Values are viewed as preferences or priorities (Kluckholn 1967; Rokeach 1968; Beyer 1981). In order to understand the role of organizational values in strategic decision making, we must distinguish them from personal values and work values. Personal values are held by individuals in a broad social context, and work values concentrate on performance in a job, but organizational values focus on the corporation and the actions the persons within that firm should select as most desirable. These values serve to define the ways in which a firm should conduct business. 


\section{The Connection between Values and Strategies}

Exactly how does the sharing of various organizational values relate to influence over strategic decisions? Clearly the sharing of some values will be more strongly associated with decision-making influence than the sharing of others. It also seems plausible that value sharing will be related to influence over some strategic issues but not associated with other issues. There is no available empirical evidence to indicate the way in which value sharing is related to influence over strategic decision making. In particular, it is not known what types of shared values are related to influence over a variety of strategic issues.

It is possible to speculate that subunits whose employees value the same things that top management values will have influence over strategic decisions that reflect these values. For example, when top management and departmental employees are similar in the value they attach to employee satisfaction, development, and morale, it is plausible that the subunit will have more influence over strategic issues which concern people, such as the level of employee service to the customer. This example suggests that similarity in the value of people is related to the ability of a subunit to influence strategic issues that require people to make a difference. In other words, by sharing specific organizational values, a subunit is more likely to possess the ability to influence specific strategic decisions.

It is the purpose of this paper to explore empirically the relationship between value sharing and influence in strategic decisions. The objective of the paper is to show that influence over strategic choices is related to value similarity. It is hypothesized that the greater the perceived similarity on people, corporate distinctiveness, operations, and performance values between a functional unit and top management, the greater the assessed ability of the unit to influence critical strategic decisions. This argument suggests that decision making is not exclusively associated with economic or market- driven actions.

Four different categories of organizational value sharing will be individually examined to ascertain whether some values are more strongly associated with influence over strategic decisions than others. Five strategic issues, regarded as critical to the organization under investigation, will be examined to determine if value sharing is associated with influence over some but not other strategic decisions.

Given the unique visionary role of founders/CEOs, value sharing with top management (vice presidents) may differ from value sharing with the CEO. Since the members of the top management team often engage in the more mundane nuts-and-bolts of the firm's operation, they may not stand out as symbols of a unique set of values. The CEO may possess a very different set of values from those of the other members of the executive team, thus providing yet another reason for examining separately value sharing with the CEO versus others in the executive group. 


\section{Methods}

Sample

The participants were 447 corporate personnel in a fast-food restaurant chain with headquarters in the Midwest. The study was conducted in two stages, beginning with interviews and followed by questionnaires. This two stage process was developed to facilitate the development of organizationally specific values and strategic decisions.

In the first state of data collection 48 employees, including all top managers and a random sample of departmental employees, were interviewed. The focus of this portion of the study was to learn which strategic decisions were the most critical and which organizational values the most important for running the firm. Content analysis of these interviews yielded a list of five critical strategic issues and 15 organizational values. This information was utilized in the development of the questionnaire; hence the results reported in this study are exclusively drawn from the survey portion of the project but reflect measures developed during the interview stage.

In the second stage of data collection 58 percent of all organizational members responded to a structured company-wide survey. Employees from all corporate departments were represented in the sample, and all respondents were asked to complete the items by thinking about their department. Relying on the department as the point of reference was made possible because of strong indications in the interviews that department members most strongly identified with their functional subunits.

\section{$\underline{\text { Measures }}$}

Strategic Decisions. In the interview stage respondents were asked to list the most critical strategic issues facing the firm. Strategic issues are those decision areas considered important to the future direction of the firm and the allocation of resources. The most frequently cited issues were as follows: (1) long-range planning; (2) increases in sales; (3) introduction of new products; (4) quality and service; and (5) major capital expenditures (acquisitions). These strategic issues were felt to be the most important facing the firm in the future, according to managers, employees, and executives. A comparison of these items with strategic priorities developed during the most recent formal strategic planning meeting of top management indicated that a consensus existed regarding the importance of these strategic decision issues. The five strategic issues selected for examination are specific to the organization studied and are not meant to represent generic strategic concerns.

Following the approach taken by Jemison (1981), we asked respondents to indicate their department's ability to affect or influence each of the five strategic decisions. Five questions were asked, one for each strategic issue, relying on a seven point scale ranging from "no ability to influence" to "greatest ability to influence," with a "don't know" option coded as missing data. 
Organizational Values. Organizational values were developed in the interviews by asking employees to list the most important values they felt an organization should have in running a firm. In addition, card sorts of values were conducted in which interviewees ranked lists of values. Based on the card sorts and frequency counts of the most important values, a list of organizational values was devised for use in the questionnaire.

Value similarity was measured in accordance with previous studies (Enz 1986) by asking respondents to indicate the degree of similarity that exists between their own functional department and top management, excluding the CEO, using the values developed during the interviews. Employees were asked separately to indicate their similarity with the CEO, using the same list of values. Each value statement used in the questionnaire was followed by a brief description in order to clarify and provide a precise interpretation of the value. Respondents were asked to indicate the degree of similarity using a seven-point scale ranging from "very dissimilar" to "very similar." A "don't know" response was available and coded as missing data.

To refine the value similarity measure, a principle component factor analysis was performed. Table 1 provides the factor loadings, eigenvalues, and percentage of variance explained by the four-factor structure which emerged. The strong loadings within the four factors indicate strong relationships between the items within each factor. The four value similarity categories include: valuing people, valuing organizational distinctiveness, valuing operations, and valuing performance. Measures of similarity for each of these four dimensions of values are obtained by adding together the scores of value items which loaded on the same factor.

People Values. People values refer to the sharing of values dealing with the positive feeling and support of employees, the openness of information exchange, and concern for the development of employee skills. Reliabilities (Cronbach alphas) for this five-item measure were .89 for similarity with top management and .87 for similarity with the CEO.

Corporate Distinctiveness Value. Similarity of corporate distinctiveness values include values dealing with the unique identity of the firm, the aggressiveness of the company, and the ability of the firm to be an industrial leader. Cronbach alphas of .78 and .76 were found for similarity with top management and the CEO, respectively.

Operations Values. Making a good product, meeting the needs of the customer, producing the product with minimal effort, waste, and expense, and behaving in a business-like manner are all aspects of operations values. The internal consistency reliabilities for this threeitem measure were .75 and .72 , respectively, for similarity with top management and similarity with the chief executive.

Performance Values. The final measure of value similarity is concerned with performance values. Performance values include making a profit, staying in business, developing new products, and reducing the cost of employing workers. Cronbach alphas of .73 
for similarity with top management and .75 for similarity with the chief executive were found for this four-item measure.

\begin{tabular}{|c|c|c|c|c|c|c|c|c|}
\hline \multicolumn{9}{|c|}{ FACTORS } \\
\hline Values & \multicolumn{2}{|c|}{$\begin{array}{c}1 \\
\text { People Values } \\
\text { w/ Top Mgmt w/CEO }\end{array}$} & \multicolumn{2}{|c|}{$\begin{array}{c}2 \\
\text { Corporate } \\
\text { Distinctiveness } \\
\text { w/Top Mgmt w/CEO }\end{array}$} & \multicolumn{2}{|c|}{$\begin{array}{c}3 \\
\text { Operations } \\
\text { Values } \\
\text { w/Top Mgmt w/CEO }\end{array}$} & \multicolumn{2}{|c|}{$\begin{array}{c}4 \\
\text { Performance } \\
\text { Values } \\
\text { w/ Top Mgmt w/ CEO }\end{array}$} \\
\hline Support Failures & .74 & .73 & .20 & .21 & .12 & .09 & .14 & .04 \\
\hline High Morale & .74 & .75 & .24 & .25 & .28 & .21 & .08 & .19 \\
\hline Employee Satisfaction & .78 & .73 & .14 & .13 & .19 & .24 & .22 & .25 \\
\hline Open Communication & .77 & .70 & .15 & .19 & .13 & .23 & .27 & .15 \\
\hline Employee Development & .79 & .74 & .12 & .13 & .20 & .27 & .18 & .20 \\
\hline Company Individuality & .16 & .20 & .87 & .81 & .08 & .08 & .05 & .17 \\
\hline Aggressiveness & .16 & .18 & .76 & .77 & .27 & .21 & .22 & .27 \\
\hline Industry Leader & .26 & .37 & .67 & .73 & .18 & .13 & .21 & .18 \\
\hline Professionalism & .31 & .38 & .35 & .30 & .66 & 67 & -.02 & -.04 \\
\hline Efficiency & .24 & .25 & .08 & .00 & .75 & .68 & .17 & .29 \\
\hline $\begin{array}{l}\text { Superior Quality } \\
\text { and Service }\end{array}$ & .1 & .26 & .15 & .15 & .76 & .74 & .22 & .13 \\
\hline Profits & .09 & -.03 & .17 & .28 & .47 & .47 & .55 & .60 \\
\hline Survival & .12 & .05 & .09 & .34 & .24 & .25 & .74 & .61 \\
\hline Creative Product & & & & & & & & \\
\hline Development & .27 & .37 & .25 & .19 & -.04 & -.07 & .67 & .69 \\
\hline Reduced Labor Costs & .46 & .43 & .04 & .09 & .16 & .18 & .61 & .67 \\
\hline Eigenvalue & 6.29 & 6.51 & 1.41 & 1.38 & 1.17 & 1.11 & 1.02 & .93 \\
\hline$\%$ Variance & 42.00 & 43.40 & 9.40 & 9.20 & 7.80 & 7.40 & 6.80 & 6.20 \\
\hline
\end{tabular}

Table 1 Varimax Rotated Factor Analysis of Value Similarity

\section{Reliability and Validity of Values Measures}

Whenever new measures are developed, investigations of reliability and validity are needed. Two separate approaches were used to explore the internal consistency reliability of the values items. First, all value items were factor analyzed (see Table 1) revealing that the value items are measuring four distinct underlying value constructs. To further explore the reliability of the four value categories, coefficient alphas were calculated. This statistic is based on the average correlation among scale items and the number of items and provides a good estimate of reliability (Nunnally 1978). The coefficients in this study were consistently high, ranging from .72 to .89 with a mean of .78 . These results compare favorably with the reliability of attitudinal measures and exceed recommended standards of acceptability (Nunnally 1978). 
It is difficult to establish the convergent validity for the reported value measures since no comparable measures exists. However, the convergence of survey items on the given constructs and the ability of separate sets of value items to discriminate provide evidence of both convergent and discriminant validity. These value measures have been subjected to extensive tests of validity and reliability in a previously reported study employing congeneric measurement modeling techniques (Enz and Fryxell 1987).

\section{Results}

\section{Value Similarity and Strategic Issues}

To determine whether a relationship exists between the value similarity measures and the strategic issues, Pearson product-moment correlations were calculated. The Pearson product-moment correlation coefficient was selected because it is the most commonly used technique to describe a relationship between two variables (Huck, Cormier, and Bounds 1974). It is important to keep in mind when interpreting the findings from this form of analysis that a strong relationship does not indicate a causal relationship.

Examination of the correlations, presented in Table 2, reveals that value similarity is most consistently associated with the ability to influence long- range planning and capital expenditures decisions and least often associated with decisions involving increases in sales. There are significant positive relationships between all four forms of value similarity with the CEO and the ability of subunits to influence long-range planning. Significant associations also exist between long-range planning and value similarity with top management on people, performance, and distinctiveness values. The issue of major capital expenditures was associated with value sharing on people, performance, and distinctiveness values regardless of the executive referent used to assess similarity. In addition, operations value similarity with the CEO was associated with the impact of functional units on increases in sales and quality/service.

Interestingly, the introduction of new products, increases in sales, and quality and service issues were not significantly associated with most of the measures of value similarity. It can be concluded that the greater the perceived value similarity on people, performance, and distinctiveness values, the greater the perceived influence of a subunit on long-range planning and major capital expenditures. In addition, the greater the value sharing between a department and the chief executive on operations values, the greater the perceived influence of the subunit on long-range planning, increases in sales, and quality/service.

It is important to note that while these correlations are significant, the size of the relationships is relatively low, indicating weak but significant associations between some forms of value similarity and perceived departmental influence on strategic issues. The lack of significant associations between some of the value-sharing categories and strategic issues suggests that value sharing may be related to some strategic decisions but not to others. In particular, influencing the strategic issues of increased sales, introduction of new products, and 
quality and service may be more strongly linked to environmental or resource dependence issues, while long-range planning and major capital expenditures are tied to value sharing.

\begin{tabular}{|c|c|c|c|c|c|c|c|c|}
\hline \multicolumn{9}{|c|}{ VALUE SIMILARITY } \\
\hline Strategic Issues & $\begin{array}{l}\text { Opera } \\
\text { Top } \\
\text { Mgmt }\end{array}$ & $\begin{array}{l}\text { s Values } \\
\text { CEO }\end{array}$ & $\begin{array}{l}\text { People } \\
\text { Top } \\
\text { Mgmt }\end{array}$ & $\begin{array}{l}\text { Values } \\
\text { CEO }\end{array}$ & $\begin{array}{l}\text { Perfor } \\
\text { Top } \\
\text { Mgmt }\end{array}$ & $\begin{array}{l}\text { nance } \\
\text { CEO }\end{array}$ & $\begin{array}{l}\text { Distincti } \\
\text { Top } \\
\text { Mgmt }\end{array}$ & $\begin{array}{l}\text { veness } \\
\text { CEO }\end{array}$ \\
\hline $\begin{array}{l}\text { Long-Range } \\
\text { Planning } \\
\text { Increases } \\
\text { in Sales } \\
\text { Introduction of } \\
\text { New Products } \\
\text { Quality \& } \\
\text { Service } \\
\text { Major Capital } \\
\text { Expenditures }\end{array}$ & $\begin{array}{l}.08 \\
.09 \\
.06 \\
.13^{*} \\
.00\end{array}$ & $\begin{array}{l}.18^{* *} \\
.10^{*} \\
.08 \\
.12 * \\
.07\end{array}$ & $\begin{array}{l}.27 * * * \\
.04 \\
.11^{*} \\
.02 \\
.23^{* * * *}\end{array}$ & $\begin{array}{l}.28^{* * *} \\
.07 \\
.09 \\
.07 \\
.21^{* * *}\end{array}$ & $\begin{array}{l}.15 * * \\
.02 \\
.14 * \\
-.01 \\
.24 * * *\end{array}$ & $\begin{array}{l}.15^{*} \\
-.03 \\
.06 \\
-.03 \\
.23^{* * * *}\end{array}$ & $\begin{array}{l}.22 * * * \\
.07 \\
.02 \\
.01 \\
.18 * *\end{array}$ & $\begin{array}{l}.10 * * \\
.07 \\
.02 \\
.06 \\
.18 * *\end{array}$ \\
\hline
\end{tabular}

Top Management: $n=244$

CEO: $n=227$

$* \mathrm{p}<.05$

$* * \mathrm{p}<.01$

$* * * \mathrm{p}<.001$

Table 2 Correlations between Value Similarity and the Ability to Influence Strategic Issues

\section{$\underline{\text { Value Differences }}$}

To explore further the connection between value sharing and departmental influence over strategic decisions, we split respondents into high- and low-value similarity groups. While the correlational analysis just reported describes the nature of the relationship between two variables, it may not clearly illustrate the magnitude of the relationship. By splitting the sample at the median, equal numbers of respondents are placed in high-and low-value similarity groups, and we can explore a more robust examination of relationships (Dalton and Kesner 1983).

Several one-way analyses of variance (ANOVAs) were employed to compare the highand low-value congruity groups for differences. ANOVAs were performed for each of the five strategic issues and four value-sharing categories to determine whether perceived influence over strategic issues differed depending on the level of value similarity. The ANOVAs are combined in Table 3 into one summary representing similarity with top management, excluding the chief executive. Each of the 20 analyses is related to a different strategic issue and valuesharing category. 


\begin{tabular}{|c|c|c|c|c|c|c|c|c|c|c|c|c|}
\hline \multicolumn{13}{|c|}{$\begin{array}{c}\text { Value Similarity } \\
\text { with Top Management }\end{array}$} \\
\hline \multirow[t]{2}{*}{ Strategic Issues } & \multicolumn{3}{|c|}{ Operations } & \multicolumn{3}{|c|}{ People } & \multicolumn{3}{|c|}{ Performance } & \multicolumn{3}{|c|}{ Distinctiveness } \\
\hline & df & MS & $\mathrm{F}$ & df & MS & F & $d f$ & MS & $\mathbf{F}$ & df & MS & $\mathrm{F}$ \\
\hline Long Range Planning & & & & & & & & & & & & \\
\hline Between & 1 & 1.51 & .57 & 1 & 54.56 & $23.54 * * *$ & 1 & 21.32 & $8.84^{* *}$ & 1 & 27.00 & $10.74^{* *}$ \\
\hline Within & 361 & 2.63 & & 298 & 2.32 & & 320 & 2.41 & & 332 & 2.51 & \\
\hline Increases in Sales & & & & & & & & & & & & \\
\hline Between & 1 & 17.81 & $6.92^{* *}$ & 1 & 4.40 & 1.63 & 1 & 6.71 & 2.60 & 1 & 11.98 & $4.68^{* *}$ \\
\hline Within & 363 & 2.57 & & 298 & 2.70 & & 322 & 2.58 & & 334 & 2.56 & \\
\hline $\begin{array}{l}\text { Introduction of } \\
\text { New Products }\end{array}$ & & & & & & & & & & & & \\
\hline Between & 1 & 7.56 & 2.05 & 1 & 32.94 & $9.21 * *$ & 1 & 26.32 & $7.39 * *$ & 1 & 8.96 & 2.47 \\
\hline Within & 364 & 3.69 & & 299 & 3.58 & & 322 & 3.56 & & 335 & 3.62 & \\
\hline Quality \& Service & & & & & & & & & & & & \\
\hline Between & 1 & 29.27 & $10.76^{* * *}$ & 1 & .06 & .02 & 1 & .01 & .00 & 1 & 9.44 & 3.66 \\
\hline Within & 361 & 2.72 & & 296 & 2.70 & & 319 & 2.63 & & 332 & 2.58 & \\
\hline Major Capital & & & & & & & & & & & & \\
\hline Expenditures & & & & & & & & & & & & \\
\hline Between & 1 & .52 & .16 & 1 & 40.97 & $13.32^{* * *}$ & 1 & 31.97 & $10.00^{* *}$ & 1 & 14.70 & $4.38^{*}$ \\
\hline Within & 347 & 3.38 & & 288 & 3.08 & & 307 & 3.20 & & 316 & 3.56 & \\
\hline
\end{tabular}

$* \mathrm{p}<.05 * * \mathrm{p}<.01 * * * \mathrm{p}<.001$

Table 3 One Way analyses of Variance for Strategic Issues Grouped by Degree of Value Similarity with Top Management

The results show significant differences in perceived departmental influence on strategic issues between high- and low-value similarity groups on some but not all issues. The largest number of differences in strategic influence were found for the issue of long-range planning and capital expenditures. High- and low-value similarity on people and performance values were found most often to produce differences in perceived departmental influence.

Differences between high- and low-value similarity on operations values were found to be significant for only two strategic decisions, those involving increased sales and quality/service. Differences in people and performance value sharing were both found to influence the introduction of new products.

Shifting to value similarity with the CEO revealed similar findings. Table 4 provides the summaries of several one-way ANOVAs for each strategic issue and value category. Once again, differences between high- and low-value congruent groups influenced perceptions of a subunit's ability to affect some strategic decisions. For each of the five strategic issues, high and low levels of similarity on operations values yielded significant differences. Differences in 
similarity on people and distinctiveness values did not as consistently influence strategic decisions. Finally, high and low levels of similarity on performance values yielded significant differences on three of the five strategic issues.

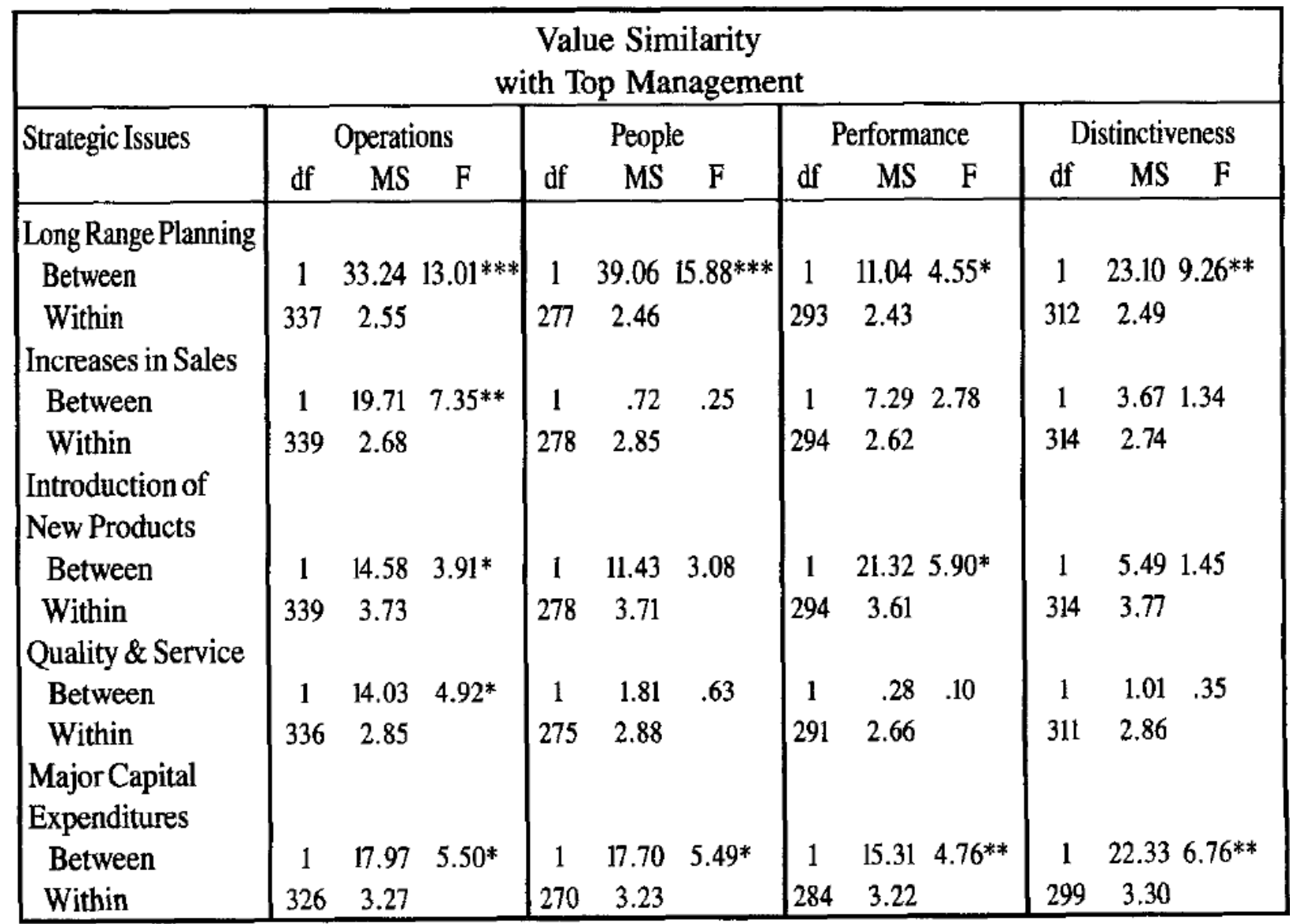

$* \mathrm{p}<.05 * * * \mathrm{p}<.01 \quad * * * \mathrm{p}<.001$

Table 4 One Way analyses of Variance for Strategic Issues Grouped by Degree of Value Similarity with the Chief Executive Officer

\section{Top Management versus the Chief Executive}

While it was thought that value similarity with top management might have a different effect on the ability of subunits to influence strategic issues than on value sharing with the chief executive, the findings of this study did not yield significant differences. This conclusion is based on comparing the number of significant correlations between the two forms of value similarity and the strategic issues.

\section{Discussion and Conclusions}

This study shows that sharing values is related to departmental influence over some strategic issues. The greater the value similarity between a department and top managers, the more likely that the subunit will be perceived by its members to affect some strategic issues. 
Simply stated, subunit employees who see the unit as sharing operations, people, performance, and distinctiveness values with company executives are more likely to view their subunit as having influence over strategic issues, such as long-range planning and capital expenditures.

In the present investigation the relationships between influences on long-range planning and capital expenditures were more strongly related to the various categories of value sharing than other issues were. Other strategic issues were affected by the sharing of some categories of value but not others. These findings show that value sharing with the executives may selectively influence the strategic decision-making process. It is likely that value sharing influences the ability of a functional unit to affect strategic issues when other factors, such as control of resources or environmental constraints, do not play a critical role. Clearly not all influence over strategic issues is affected by value sharing.

Another explanation for why value sharing is associated with some but not other strategic issues may be due to the unconscious or taken-for-granted role of value sharing. It is possible that value sharing is a precursor to the "rational" explanations for strategic influence. That is, those functional units regarded as most similar to top management may have a greater opportunity to control resources or define the relevant environmental constraints (Enz 1986). Values may guide all strategic decisions and organizational actions, but some of them may be attributed to rational explanations or economic logic at a later date. It is possible that value sharing makes it possible to influence strategic decisions, and rational explanations follow as post hoc interpretations of the process. These rational interpretations may be preferred by the value congruent because of their appearance as more legitimate in the eyes of the value incongruent.

In conclusion, this study has provided preliminary support for value sharing as a factor in departmental strategic involvement. The perceived ability of functional units to be involved in critical strategic decisions is related to the subunit's similarity with executives on organizational values. Future research should continue to refine the questions of which categories of value sharing and which specific strategic issues are relevant in the values/strategy relationship. In addition, researchers should continue to consider the subtle and primary role value sharing plays in the development and legitimation of rational explanations of organizational functioning.

\section{Acknowledgement}

The author wishes to acknowledge the comments of Dan E. Dalton, Gerald Fryxell, and Charles Schwenk on an earlier version of this article.

\section{References}

Andrews, K. R. 1980. The Concept of Corporate Strategy. Homewood: Irvin.

Barnard, C. I. 1938. The Functions of the Executive. Harvard UR 
Barney, J. B. 1986. “Organizational Culture: Can It be a Source of Sustained Competitive Advantage?" Academy of Management Review 11: 656-65.

Beyer, J. M. 1981. "Ideologies, Values, and Decision-Making in Organizations." Handbook of Organizational Design: Vol 1. Ed. P. C. Nystrom and W. H. Starbucks. New York: Oxford UP. 166-202.

Blau, P. M. 1967. Exchange and Power in Social Life. New York: John Wiley and Sons.

Child, J. 1972. "Organizational Structure, Environment, and Performance: The Role of Strategic Choice." Sociology 6: 2-22.

Dalton, D. R., and I. F. Kesner. 1983. "Inside/Outside Succession and Organizational Size: The Pragmatics of Executive Replacement." Academy of Management Journal 26.4: 736-42.

Enz, C. A. 1986. Power and Shared Values in the Corporate Culture. Ann Arbor: UMI Research Press.

Enz, C. A., and G. E. Fryxell. 1987. "The Meaning and Measurement of Organizational Value Congruity." National Academy of Management Meetings.

Hambrick, D. C., and P. A. Mason. 1984. "Upper Echelons: The Organization as a Reflection of Its Top Managers." Academy of Management Review 9: 193-206.

Huck, S. W., W. H. Cormier, and W. G. Bounds. 1974. Reading Statistics and Research. New York: Harper and Row.

Jemison, D. 1981. “Organizational Versus Environmental Sources of Influence in Strategic Decision Making." Strategic Management Journal 2:77-89.

Kluckholn, C. 1967. "Values and Value-Orientations in the Theory of Action." Toward a General Theory of Action. Ed. T. Parsons and E. A. Shils. New York: Harper and Row. 388-433.

Lorange, P. 1980. Corporate Planning. Englewood Cliffs: Prentice-Hall.

March, J. G., and H. A. Simon. 1958. Organizations. New York: John Wiley and Sons.

Mintzberg, H., D. Raisinghani, and A. Theoret. 1976. "The Structure of Unstructured Decision Processes. Administrative Science Quarterly 21: 24675.

Murray, E. A. 1978. "Strategic Choice as a Negotiated Outcome." Management Science 24: 96073.

Narayanan, V. K., and L. Fahey. 1982. "The Micro-Politics of Strategy Formulation." Academy of Management Review 7: 25-34. 
Nunnally, J. C. 1978. Psychometric Theory. New York: McGraw Hill.

Rokeach, M. 1968. Beliefs, Attitudes, and Values. San Francisco: Jossey- Bass.

Selznick, P. 1957. Leadership in Administration: A Sociological Interpretation. Evanston: Row, Peterson.

Simon, H. A. 1957. Administrative Behavior. New York: Free Press. 